\title{
Relationship between oxidative stress and erectile function
}

Thierry Roumeguère, Pierre Van Antwerpen, Henda Fathi, Alexandre Rousseau, Luc Vanhamme, Thierry Franck, Carla Costa, Annamaria Morelli, Christophe Lelubre, Claude Hauzeur, Martine Raes, Didier Serteyn, Eric Wespes, Michel Vanhaeverbeek \& Karim Zouaoui Boudjeltia

To cite this article: Thierry Roumeguère, Pierre Van Antwerpen, Henda Fathi, Alexandre Rousseau, Luc Vanhamme, Thierry Franck, Carla Costa, Annamaria Morelli, Christophe Lelubre, Claude Hauzeur, Martine Raes, Didier Serteyn, Eric Wespes, Michel Vanhaeverbeek \& Karim Zouaoui Boudjeltia (2017) Relationship between oxidative stress and erectile function, Free Radical Research, 51:11-12, 924-931, DOI: 10.1080/10715762.2017.1393074

To link to this article: https://doi.org/10.1080/10715762.2017.1393074

Accepted author version posted online: 17

Oct 2017.

Published online: 08 Nov 2017.

Submit your article to this journal ๔

Џ Article views: 76

Q View related articles ¿

View Crossmark data $־$

Citing articles: 4 View citing articles $\longleftarrow$ 


\title{
Relationship between oxidative stress and erectile function
}

\author{
Thierry Roumeguère ${ }^{a, b}$, Pierre Van Antwerpen ${ }^{c}$, Henda Fathi $^{b}$, Alexandre Rousseau ${ }^{a}$, Luc Vanhamme ${ }^{d}$, \\ Thierry Franck ${ }^{\mathrm{e}}$, Carla Costa ${ }^{\mathrm{f}}$, Annamaria Morelli ${ }^{\mathrm{g}}$, Christophe Lelubre $^{\mathrm{a}}$, Claude Hauzeur ${ }^{\mathrm{h}}$, Martine Raes ${ }^{\mathrm{i}}$, \\ Didier Serteyn ${ }^{\mathrm{e}}$, Eric Wespes ${ }^{\mathrm{h}}$, Michel Vanhaeverbeek ${ }^{\mathrm{a}}$ and Karim Zouaoui Boudjeltia ${ }^{\mathrm{a}}$ \\ ${ }^{a}$ Experimental Medicine Laboratory, ULB 222 Unit, ISPPC, CHU de Charleroi, A. Vésale Hospital, Montigny-Le-Tilleul, Belgium; \\ ${ }^{\mathrm{b}}$ Department of Urology, Erasme University Hospital, ULB, Brussels, Belgium; 'Laboratory of Pharmaceutical Chemistry, Institute of

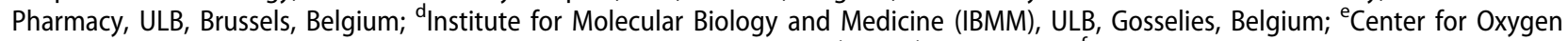 \\ Research and Development, Institute of Chemistry B6a, University of Liège, Liège, Belgium; 'Department of Experimental Biology and \\ Department of Biochemistry (U38-FCT), Faculty of Medicine of Porto, Porto, Portugal; ${ }^{9}$ Sexual Medicine and Andrology Unit, \\ Department of Clinical Physiopathology, University of Florence, Florence, Italy; ${ }^{\mathrm{h} D e p a r t m e n t}$ of Urology, CHU de Charleroi, Charleroi, \\ Belgium; 'Namur Research Institute for Life Sciences, Namur University, Namur, Belgium
}

\section{ABSTRACT}

The aim of this study was to investigate markers of inflammation and oxidative stress in the corpus cavernosum (CC) and to compare levels of inflammatory markers recorded in CC to venous blood from the arm to examine the potential impact of inflammatory parameters on erectile function and endothelial dysfunction in vitro. Ninety-seven patients with no complaint of erectile dysfunction (ED) at inclusion were prospectively included and completed the Erectile Function domain of the IIEF questionnaire. Several parameters, including lipids, MPO-dependent oxidised LDL (Mox-LDL), IL-8, IL-18, were measured. After RNA extraction, the expression of eNOS was analysed. A paired $t$-test was used for comparisons between arm and CC blood results. A two-way ANOVA was used to estimate the effects of IL-18 and IL-8 on the IIEF score. Mean patient age was $59 \pm 14.5$ years. IL-18, Mox-LDL, and Mox-LDL/ApoB levels were significantly increased in CC compared to arm blood. The IIEF score was correlated with IL-18 levels in the venous blood $(\mathrm{R}=-0.31, p=.003)$ and in the $\mathrm{CC}(\mathrm{R}=-0.37, p=.004)$ and with IL-8 $(\mathrm{R}=-0.31, p=.009$ and $\mathrm{R}=-0.28$, respectively, $p=.02$ ). There was a significant effect with the IL-18 on IIEF potentiated by high serum IL-8 concentrations. IL-18 and Mox-LDL significantly decreased eNOS mRNA expression in human aortic endothelial cell line (HAEC). These preliminary results address the importance of inflammation in the CC and highlight a difference in marker concentrations between venous and CC blood. However, they do not show any difference in terms of clinical erectile score predictivity. Involvement of inflammatory cytokines isolated in CC in the genesis of ED requires further studies.

\section{ARTICLE HISTORY}

Received 11 November 2016 Revised 25 September 2017 Accepted 11 October 2017

\section{KEYWORDS}

Erectile function; oxidative stress; inflammation; corpus cavernosum; cardiovascular disease

\section{Introduction}

Erectile dysfunction (ED) is a common disorder where oxidative stress impairs endothelial function leading to the development of ED and cardiovascular diseases (CVD) [1]. Its incidence increases with age, affecting the quality of sexual and emotional life of men and their partners [2]. ED is mainly of vascular origin and is linked to several risk factors that are shared with atherosclerosis, including being overweight, smoking, physical inactivity, and lipid disorders responsible for oxidative stress $[3,4]$. The link between these risk factors appears to be endothelial dysfunction. Endothelial dysfunction is thus the common denominator of CVD and ED.
Endothelial cells of the corpus cavernosum (CC) contribute to the production of nitric oxide (NO), which has a major role in maintaining erectile function. NO stimulates the formation of cyclic GMP (cGMP), which leads to smooth muscle relaxation, facilitating erection. An anomaly in the NO/cGMP pathway may lead to the development of ED [5]. ED is considered as a clinical manifestation of functional and structural vascular abnormalities affecting the penile circulation and may evolve as part of systemic CVD. Indeed, oxidative stress and inflammation, both initiating CVD, can induce endothelial dysfunction with a reduction in the biosynthesis of NO. The role of lipids in the formation and evolution of the atherosclerotic plaque is also well

CONTACT Thierry Roumeguere Thiery.roumeguere@erasme.ulb.ac.be Belgium 
established [6]. The development of the atherosclerotic plaque involves the intervention of macrophages, recruitment of lymphocytes, and accumulation of oxidised low-density lipoproteins (LDL). Myeloperoxi-dase (MPO), an enzyme found in neutrophils and monocytes, is partly responsible for the formation of oxidised LDL and is considered as an inducer of endothelial dysfunction and a cardiovascular risk factor [7,8]. LDL oxidised by MPO (Mox-LDL) were shown to be present in the CC of patients with ED of vascular origin [9]. In vitro, MoxLDL induce an inflammatory response by increasing the production of cytokines, such as interleukin-8 (IL-8), by endothelial cells and decreasing the concentration of cGMP, the second mediator involved in the relaxation of smooth muscle cells, the major factor in the physiological mechanism of erection $[10,11]$.

ED has also been shown to be associated with other circulating inflammatory parameters, such as high sensitivity C-reactive protein (hs-CRP), IL-1 $\beta$ and tumour necrosis factor (TNF)- $\alpha$ [12]. IL-18 is a proatherogenic cytokine that amplifies the inflammatory cascade by stimulating the expression of other proinflammatory cytokines, such as IL-8 and adhesion molecules. Chandrasekar et al. demonstrated that IL-18 activates both intrinsic and extrinsic proapoptotic signalling pathways, inducing endothelial cell death or apoptosis [13]. A recent meta-analysis reported that circulating IL18 is prospectively and independently associated with cardiovascular disease risk [14].

The primary objective of this study was to investigate the relationship between markers of inflammation, in particular IL-18, MPO, and Mox-LDL in the CC and erectile function score. Secondary aims were to compare the levels of inflammatory markers recorded in CC and peripheral blood and to examine, using an endothelial cell line, the potential impact of inflammatory parameters (Mox-LDL and IL-18) in endothelial dysfunction and eNOS mRNA expression in vitro.

\section{Materials and methods}

\section{Patient selection and clinical characterisation}

After approval by the Ethics Committee of Erasme-ULB hospital, 97 patients aged over 18 years (20-84 years) with no complaints of clinical ED, who were hospitalised in the Urology Department of Erasme-ULB hospital for endoscopic procedures, were prospectively included in the study between January and May 2010. All subjects signed an informed consent form specifying the purpose of the study and methods of blood sampling.

On inclusion, the following data were recorded: body mass index (BMI), comorbidities (diabetes, hypertension, ischemic cardiomyopathy, dyslipidaemia, smoking history, depression) and medications. The part of the "International Index of Erectile Function" questionnaire corresponding to the five questions devoted to the erectile function domain score (IIEF-EF) was completed by each participant. A lower score corresponds normally to a higher severity of ED in clinical setting.

Under general or spinal anaesthesia, and before starting each procedure (including bladder catheter insertion if any), a venous blood sample $(8-10 \mathrm{ml})$ was collected and placed in a dry tube and a citrate tube, followed by a nonporous sample of about $4-8 \mathrm{ml}$ from the CC using an 18-gauge needle. The samples were then centrifuged for $10 \mathrm{~min}$ at $3000 \mathrm{~g}$ and the supernatant collected and frozen. Blood tests were performed at the Laboratory of Experimental Medicine of the University Hospital of Charleroi, site A. Vésale, Unit 222, ULB. The following parameters were measured: Total plasma testosterone, C-reactive protein (CRP), blood glucose, glycosylated haemoglobin ( $\mathrm{HbA} 1 \mathrm{c})$, total cholesterol, triglycerides, HDL-cholesterol (standard laboratory techniques PLC), and adiponectin.

LDL-cholesterol levels were calculated using the Friedewald formula (LDL-C $=\mathrm{TC}-\mathrm{HDL}-\mathrm{c}-\mathrm{TG} / 5$ (mg/ $\mathrm{dl})$ ). The antibodies used for the measurements of MoxLDL have been fully characterised previously [15]. The MPO content in plasma was measured using ELISA tests (ELIZEN MPO, Zentech SA, Belgium) [16].

\section{Cytokine quantification}

IL-8 and IL-18 serum concentrations were quantified using an ELISA test (Becton Dickinson ${ }^{\circledR}$, Franklin Lakes, NJ, USA).

\section{Incubation of endothelial cells with native and oxidised LDL and cytokines}

Human aortic endothelial cell line (HAEC) (Lonza), a human aortic endothelial primary cell obtained at passage 2. These cells are very well characterised and were cultured in Endothelial Cell Basal Medium-two and the following growth supplements: hydrocortisone, basic fibroblast growth factor, vascular endothelial growth factor, insulin-like growth factor, ascorbic acid, heparin, FBS, human epidermal growth factor, gentamicin, amphotericin B (Lonza). Experiments were performed at passage 4 where native LDL and MoxLDL $(100 \mu \mathrm{g} / \mathrm{ml}), \quad$ IL-18 $(250 \mathrm{pg} / \mathrm{ml})$ and TNF- $\alpha$ $(10 \mathrm{ng} / \mathrm{ml})$, sterilised by filtration through a $0.22-\mathrm{mm}$ membrane (Millipore), were added to the culture medium and incubated with the endothelial cells for 24 hours at $37{ }^{\circ} \mathrm{C}$ under $5 \% \mathrm{CO}_{2}$. The experiments were performed in triplicate. 


\section{Isolation and oxidation of lipoproteins}

Low-density lipoproteins were isolated from pooled plasma from healthy males using sequential ultracentrifugation [17]. LDL fractions $(d=1.019-1.063)$ were stored at $4{ }^{\circ} \mathrm{C}$ in the dark. Prior to oxidation, LDL was gel filtered (PD-10 column, Pharmacia) and $1.6 \mathrm{mg}$ of $\mathrm{LDL}$ was oxidised at $37^{\circ} \mathrm{C}$ in the presence of 2.6 chlorinating units of recombinant MPO [18] and $1 \mathrm{mmol} / \mathrm{L}$ $\mathrm{H}_{2} \mathrm{O}_{2}$ in PBS at $\mathrm{pH}=6.5$ for 5 min to form fraction $\mathrm{B}$ of MPO-dependent oxidised LDL (Mox-LDL, 15). The reaction was stopped on ice. The concentration of LDL in samples was determined according to the Lowry method.

\section{Characterisation of Mox-LDL}

Mox-LDL have been characterised previously $[10,15,19]$. However, native or Mox-LDL were routinely controlled by loading them onto a 1\% agarose gel (Beckman). After electrophoresis $(120 \mathrm{~V}, 30 \mathrm{~min})$ in barbital buffer, fixation was performed in a solution of $30 \%$ methanol $-20 \%$ acetic acid. The gel was stained in Paragon blue stain solution and destaining was carried out in a solution of $5 \%$ acetic acid. The presence of a characteristic band corresponding to Mox-LDL allowed us to verify that the oxidation process succeeded as Mox-LDL has increased electrophoretic mobility compared to LDL.

\section{RNA extraction}

After treatment, cells were washed with cold PBS and total RNA was extracted using the RNeasy kit, according to the manufacturer's protocol (Qiagen, Hilden, Germany). Extracts were stored at $-80^{\circ} \mathrm{C}$.

\section{Gene expression analysis}

RNA concentration and integrity were evaluated with a NanoDrop spectrophotometer (Thermo Scientific, Waltham, MA, USA). RNA ( $1 \mu \mathrm{g})$ was reverse transcribed, using a Transcriptor High Fidelity cDNA Synthesis Kit (Roche). Real-time qPCR assays were performed with a Light Cycler 480 (Roche, Basel, Switzerland), using $400 \mathrm{ng}$ of cDNA per reaction and SYBR-Green dye. The expression of endothelial NO synthase (eNOS) was assessed using the following primers obtained from Merck (Darmstadt, Germany; formerly Sigma-Aldrich, St Louis, MO, USA): Forward primer - AGGAACCTGTGTGACCCTCA; reverse primer - CGAGGTGGTCCGGGTATCC. The 1.5.0 SP4 software from Light Cycler 480 was used for calculations. The relative level of expression was measured by the comparative $\mathrm{CT}(\Delta \Delta \mathrm{CT})$ method with
HMBS (forward primer: AAGTGCGAGCCAAGGACCAGGA; reverse primer: CAGCGATGCAGCGAAGCAGAGT), GAPDH (forward primer: ACCCACTCCTCCACCTTTGAC; reverse primer: GTCCACCACCCTGTTGCTGTA) and $18 \mathrm{~S}$ (forward primer: TGGTGCATGGCCGTTCT; reverse primer: TAGTTAGCATGCCAGAGTCTCGTT) genes as references.

\section{Statistical analysis}

Sigma Stat 3.0 software SPSS (San Jose, CA, USA) was used for statistical analysis. Differences were considered statistically significant with a two-tailed $p<.05$. Comparisons between arm and CC blood results were made using a Wilcoxon's signed rank test. Univariate analyses were depicted by Pearson's coefficient. Several models of multiple linear regression analysis were tested including nine variables of interest. The standardised regression coefficients and $p$ value is reported for each model. For multiple linear correlations some values were transformed into "log" to respect homoscedasticity.

\section{Results}

\section{Clinical characteristics and univariate analysis}

Clinical characteristics and biological parameters, known to be important in ED or CVD, were recorded from the patients as shown in Table 1. No clinically relevant cardiovascular diseases nor arthritis were registered. Despite no complaint of ED, the patients admitted for endoscopy had a mean IIEF-EF score of $15+/-9.5$, reflecting a wide variation of interpretation from no to severe erectile dysfunction. IL-18, Mox-LDL and Mox$\mathrm{LDL} / A p o B$ levels were significantly higher in the CC blood compared to the arm. It is noteworthy that the IL-18 levels are higher than the values reported in literature for healthy subjects [20]. In contrast, adiponectin, $A p o B$ and ApoA-1 levels were significantly lower in blood from the CC than from the arm. No difference was observed in IL-8 levels. Haematocrits were compared between arm blood and CC with no difference suggesting, as a valid argument, the absence of an haemodilution or concentration phenomenon $(n=20$, $p=.45$, Supplement data 1 ).

Univariate analysis showed that the IIEF score was negatively correlated with IL-18 levels in the arm $(\mathrm{R}=-0.31, p=.003)$ and in the $\mathrm{CC}(\mathrm{R}=-0.37, p=.004$, Figure 1). The IIEF was also negatively correlated with IL-8 in the $\operatorname{arm}(R=-0.31, p=.009)$ and in the CC $(\mathrm{R}=-0.28, p=.02)$. In contrast, there was no correlation between BMI and IL-18 levels in the arm and CC $(p=.37$ 
Table 1. Patient cohort characteristics.

\begin{tabular}{|c|c|c|c|c|}
\hline \multirow[b]{2}{*}{$N=97$} & \multirow[b]{2}{*}{ All } & \multicolumn{2}{|c|}{ Blood sampling site } & \multirow[b]{2}{*}{$p$ value } \\
\hline & & Arm & Corpus Cavernosum & \\
\hline IIEF-EF & $19(6-24)$ & & & \\
\hline Age (years) & $61(49-71)$ & & & \\
\hline BMI $\left(\mathrm{kg} / \mathrm{m}^{2}\right)$ & $26(24-29)$ & & & \\
\hline Diabetes & $13(13.4 \%)$ & & & \\
\hline Smokers & $27(28 \%)$ & & & \\
\hline Glycemia (mg/dl) & & $98(87-111)$ & & \\
\hline HbA1c (\%) & & $5.7(5.3-6.1)$ & & \\
\hline Testosterone (ng/ml) & & $4(3-5.4)$ & & \\
\hline Adiponectin (pg/ml) & & $8137(419-19218)$ & 7476 (429-13968) & $<.001$ \\
\hline IL-18 (pg/ml) & & $328(267-430)$ & $365(286-508)$ & $<.001$ \\
\hline IL-8 (pg/ml) & & $12.9(9.4-19.7)$ & $11.2(8-19.7)$ & .1 \\
\hline Mox-LDL $(\mu \mathrm{g} / \mathrm{ml})$ & & $5.4(4.4-9.4)$ & $10(5.5-23.1)$ & .001 \\
\hline MPO ( $\mu \mathrm{g} / \mathrm{ml})$ & & $31(20.8-60)$ & $46.5(25.6-95.9)$ & .02 \\
\hline Mox-LDL/ApoB $\times 10^{-3}$ & & $7.1(5.2-11)$ & $11(7-16)$ & .005 \\
\hline Total cholesterol $(\mathrm{mg} / \mathrm{dl})$ & & $174(149-209)$ & & \\
\hline Triglycerides (mg/dl) & & $108(69-131)$ & & \\
\hline HDL-c (mg/dl) & & $47(40-53)$ & & \\
\hline ApoB (mg/dl) & & 80 (64-97) & $77(66-92)$ & $<.001$ \\
\hline ApoA (mg/dl) & & $126(110-144)$ & 118 (109-139) & $<.001$ \\
\hline
\end{tabular}

$p$ value: Wilcoxon's Signed Rank test.

(A)

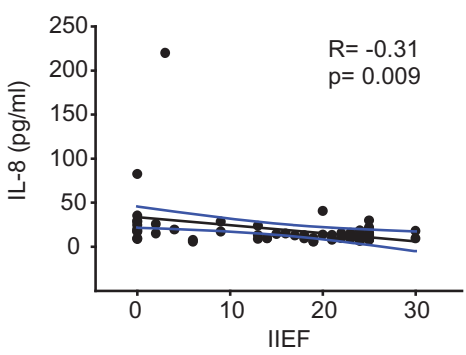

(D)

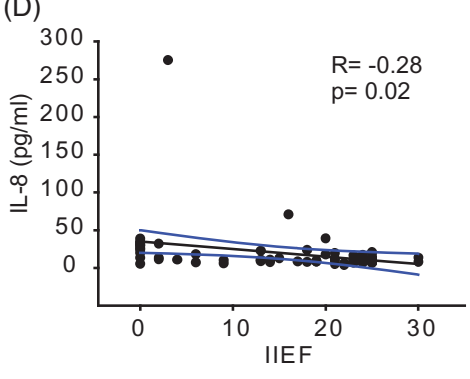

(B)

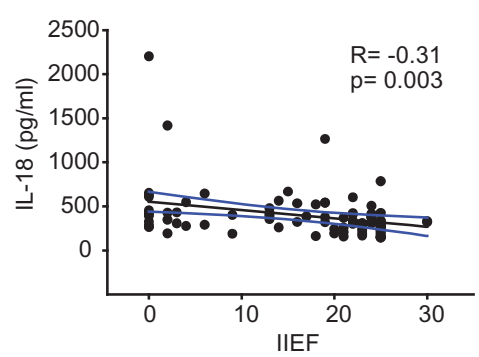

(E)

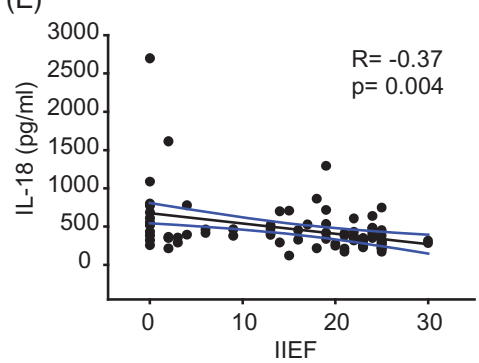

(C)

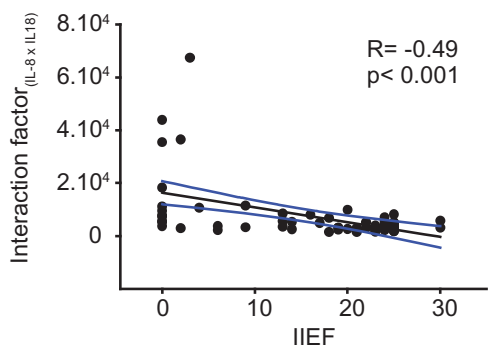

(F)

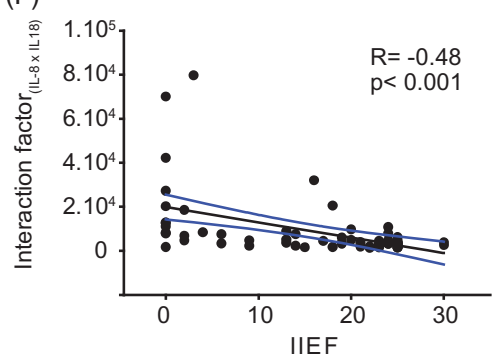

Figure 1. Correlation between IIEF score and IL-8 and IL-18 levels in arm and corpus cavernosum.

and .66, respectively) nor between IL-18 and glycemia or $\operatorname{HbA1c}(p=.7$ and .1 , respectively).

Table 2 shows correlations between arm and CC for the measured parameters. The IL- 8 in arm is well correlated with the IL-8 in CC $(\mathrm{R}=0.6 ; p<.001)$. IL-18 in arm is also well correlated with IL-18 in CC $(R=0.74$; $p<.001)$. Globally, a good correlation between blood parameters and CC parameters are observed.

\section{Multilinear regression analysis}

We investigated whether an explanatory correlation could be found between any of the analysed parameters using a multivariate analysis. We ran a first model
(Model-1, Table 3) in which the IIEF score was the dependent variable and age, BMI, smoking habit, diabetes, IL-18, IL-8, adiponectin, Mox-LDL, and testosterone in blood from the arm were independent variables. Significant associations were found between IIEF and IL$18, \mathrm{IL}-8$ and age but not between IIEF and any other parameters. We ran a second model (Model-2, Table 3) using the same parameters but measured in CC blood. The associations between the IIEF and IL-18, IL-8 and age were confirmed. The $r^{2}$ values for the two models were 0.493 (arm) and 0.497 (CC), suggesting that nearly $50 \%$ of the variability in the IIEF in this group could be explained by these variables, with IL-18 as the most prominent explanatory variable. 
Table 2. Correlations between arm and corpus cavernosum parameters.

\begin{tabular}{lccccc}
\hline $\mathrm{R}(\mathrm{p})$ & $\begin{array}{c}\text { Adiponectin } \\
\text { arm }\end{array}$ & $\begin{array}{c}\mathrm{IL}-8 \\
\mathrm{arm}\end{array}$ & $\begin{array}{c}\mathrm{IL}-18 \\
\mathrm{arm}\end{array}$ & $\begin{array}{c}\text { Mox-LDL } \\
\text { arm }\end{array}$ & $\begin{array}{c}\text { Mox-LDL/ApoB } \\
\text { arm }\end{array}$ \\
\hline $\begin{array}{l}\text { Adiponectin CC } \\
\text { IL-8CC }\end{array}$ & $0.97\left(<10^{-6}\right)$ & & & & \\
IL-18CC & & $0.6\left(10^{-5}\right)$ & & & \\
Mox-LDL CC & & & $0.74\left(10^{-5}\right)$ & $0.82\left(10^{-5}\right)$ & $0.99\left(<10^{-6}\right)$ \\
Mox-LDL/ApoB CC & & & & \\
\hline
\end{tabular}

Table 3. Multiple Linear regression, Model-1 (Arm) and Model-2 (CC).

\begin{tabular}{|c|c|c|c|c|}
\hline \multirow[b]{2}{*}{$(n=97)$} & \multicolumn{2}{|c|}{ Arm } & \multicolumn{2}{|c|}{ Corpus Cavernosum } \\
\hline & $\begin{array}{l}\text { Stand. Reg } \\
\text { Coefficient }\end{array}$ & $p$ value & $\begin{array}{l}\text { Stand. Reg } \\
\text { Coefficient }\end{array}$ & $p$ value \\
\hline & \multicolumn{2}{|c|}{$\mathrm{R}^{2}=0.493 ; p=.006$} & \multicolumn{2}{|c|}{$\mathrm{R}^{2}=0.497 ; p=.005$} \\
\hline Age & -0.336 & .02 & -0.318 & .02 \\
\hline $\mathrm{BMI}$ & -0.034 & .84 & 0.004 & .97 \\
\hline Smoking Habit & -0.142 & .34 & -0.296 & .06 \\
\hline Diabetes & 0.001 & .99 & 0.011 & .94 \\
\hline IL-18 & -0.326 & .03 & -0.263 & .04 \\
\hline IL-8 & -0.338 & .05 & -0.348 & .03 \\
\hline Adiponectin & -0.85 & .55 & -0.042 & .76 \\
\hline Mox-LDL & 0.061 & .70 & -0.237 & .10 \\
\hline Testosterone & 0.081 & .56 & 0.017 & .91 \\
\hline
\end{tabular}

IIEF is the dependent variable while independent variables are: Age, BMI, smoking habit, diabetes, IL-18 (arm or CC), IL-8 (arm or CC), adiponectin (arm or CC), myeloperoxidase-modified LDL (Mox-LDL, arm or CC), testosterone.

We ran also two other multivariate models in integrating an interaction term (multiplication between IL-8 and IL-18) in arm and CC, respectively (Model-3 and Model-4, Table 4). When we introduce the interaction term, this last one is preponderant in arm and in CC models.

\section{In vitro experiments}

We performed in vitro experiments in order to investigate putative molecular mechanisms supporting the synergy between the two cytokines observed in the clinical study. First, we assessed the direct effect of IL-18 on IL-8 expression. Indeed, HAEC cells in culture were treated with concentrations within the physiologic range of IL-18 for such a population of male patients $(250 \mathrm{pg} / \mathrm{ml})[21,22]$. No induction of IL-8 expression by IL-18 stimulation could be detected. In contrast, IL-8 was stimulated by TNF- $\alpha$, LDL, and Mox-LDL (Figure 2). Unfortunately, the reverse experiment could not be performed because HAEC cells constitutively express IL-8, accumulating it in the culture medium. As no IL-18 could be detected in these conditions, it nevertheless indicates that these IL-8 concentrations are not able to trigger IL-18 expression by HAEC cells.

As endothelial function could be negatively impacted by vascular inflammatory markers on NO activity, the eNOS expression was monitored in HAEC
Table 4. Multiple Linear regression, Model-3 (Arm) and Model-4 (CC).

\begin{tabular}{|c|c|c|c|c|}
\hline \multirow[b]{2}{*}{$(n=97)$} & \multicolumn{2}{|c|}{ Arm } & \multicolumn{2}{|c|}{ Corpus Cavernous } \\
\hline & $\begin{array}{l}\text { Stand. Reg } \\
\text { Coefficient }\end{array}$ & $p$ value & $\begin{array}{l}\text { Stand. Reg } \\
\text { Coefficient }\end{array}$ & $p$ value \\
\hline & \multicolumn{2}{|c|}{$\mathrm{R}^{2}=0.455 ; p=.005$} & \multicolumn{2}{|c|}{$\mathrm{R}^{2}=0.503 ; p=.009$} \\
\hline Age & -0.206 & .12 & -0.326 & .02 \\
\hline BMI & -0.144 & 39 & -0.003 & .98 \\
\hline Smoking Habit & -0.021 & .80 & -0.305 & .06 \\
\hline Diabetes & 0.076 & .68 & 0.017 & .92 \\
\hline IL-18 & 0.381 & .11 & 0.162 & .82 \\
\hline IL-8 & -0.167 & .05 & -0.182 & .83 \\
\hline IL-18xIL-8 & -0.237 & .02 & -0.673 & .01 \\
\hline Adiponectin & 0.050 & .55 & -0.035 & .55 \\
\hline Mox-LDL & -0.112 & .40 & -0.222 & .40 \\
\hline Testosterone & 0.031 & .76 & 0.036 & .76 \\
\hline
\end{tabular}

IIEF is the dependent variable while independent variables are: Age, BMI, smoking habit, diabetes, IL-18 (arm or CC), IL-8 (arm or CC), interaction factor (IL-8 $\times$ IL-18 in arm or CC), adiponectin (arm or CC), myeloperoxidase-modified LDL (Mox-LDL, arm or CC), testosterone.

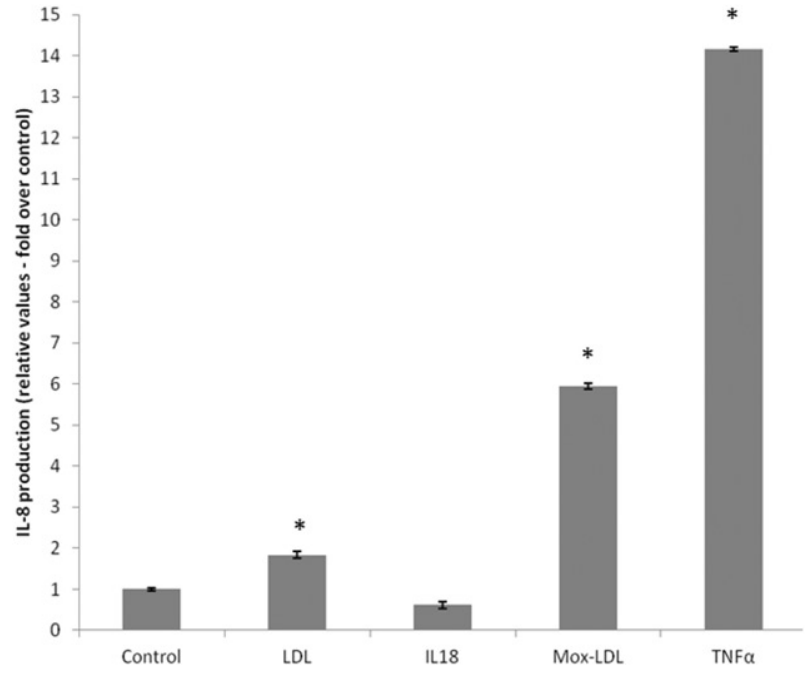

Figure 2. No direct effect of IL-18 on IL-8 expression. HAEC were exposed to Native LDL and Mox-LDL $(100 \mu \mathrm{g} / \mathrm{ml})$, IL-18 $(250 \mathrm{pg} / \mathrm{ml})$ and TNF- $\alpha(10 \mathrm{ng} / \mathrm{ml})$ for $24 \mathrm{~h}$. ANOVA $<0.001$, $*<0.05$ versus control, Bonferroni post-hoc test.

cells in culture treated with IL-18 (Figure 3). IL-18 administration caused a decrease in eNOS mRNA expression as also observed with Mox-LDL and TNF- $\alpha$.

\section{Discussion}

CVD and ED share the same risk factors and they have common denominators: oxidative stress and 


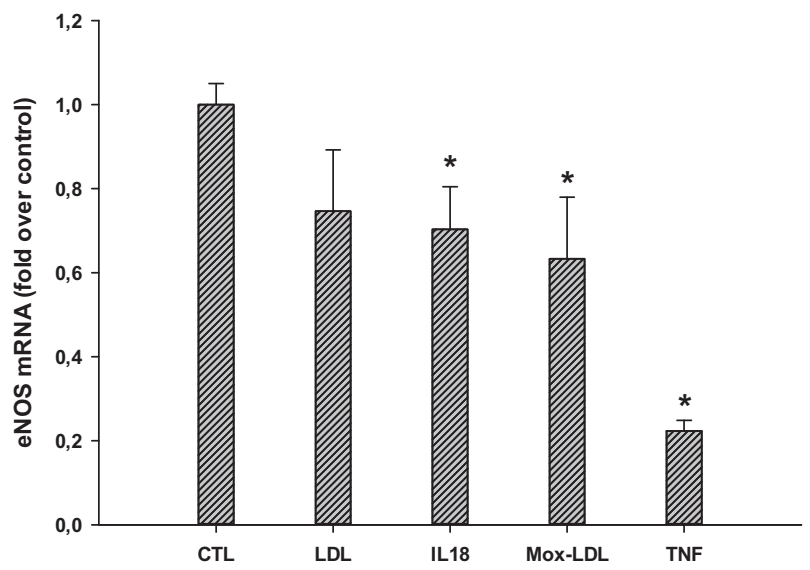

Figure 3. HAEC were exposed to Native LDL and Mox-LDL $(100 \mu \mathrm{g} / \mathrm{ml}), \mathrm{IL}-18(250 \mathrm{pg} / \mathrm{ml})$ and TNF- $\alpha(10 \mathrm{ng} / \mathrm{ml})$ for $24 \mathrm{~h}$. Three independent experiments were performed in triplicate. ANOVA $<0.001, *<0.05$ versus control, Bonferroni post-hoc test.

inflammation leading to endothelial dysfunction. However, ED is generally admitted as a predictive event for more severe cardiovascular diseases $[23,24]$. But the question remains whether the endothelial dysfunction in CC is a reflect of the systemic vascular endothelial dysfunction or a local effect. In this context, there are few reports comparing oxidative stress and inflammation in peripheral venous blood (commonly used in studies) and cavernosal blood. As we have demonstrated the presence of Mox-LDL in CC blood from patients with ED [9], we systematically measured MoxLDL in both compartments together with IL-18 and IL-8, which have been associated with CVD and ED. Indeed, proinflammatory cytokines such as IL-8 and IL-18 are found at higher circulating concentrations in obese patients with erectile and endothelial dysfunction [25].

In this study, a mean IIEF-EF score of $15+/-9.5$ was calculated in 97 patients admitted for endoscopy, whose systematic questioning did not report a clinical erectile problem, showing that an objective interpretation of the score can be difficult for clinical evaluation in some men. Nevertheless, we can notice a dispersion of the scoring among the patient population, which reinforce the correlation study between inflammatory factors and IIEF-EF score.

Univariate and multivariate analysis showed that IL-18 and IL-8, in combination or alone, were the best explanatory parameters of the IIEF-EF score variation. This observation was confirmed in peripheral and cavernosal blood. More importantly, the comparisons between the cavernosal and peripheral venous blood showed that IL-18, Mox-LDL and the Mox-LDL/ApoB ratio (which is an estimation of the fraction of blood MPO modified LDL) were significantly increased in the
CC, suggesting a local effect in CC. Interestingly, there was no difference between haematocrits and IL-8 levels in the arm or in CC blood, suggesting the absence of an haemodilution or haemoconcentration phenomenon.

Several data in literature are in favour of a local effect in CC. The capture antibody used for Mox-LDL reacts only with $\mathrm{LDL}$ modified by the $\mathrm{MPO} / \mathrm{H}_{2} \mathrm{O}_{2} / \mathrm{Cl}^{-}$system [15] and this allowed us to detect them in CC of patients with ED [9]. We also showed that the membrane-bound-nicotinamide-adenine-dinucleotide phosphate (NADPH) oxidase of endothelial cells plays a central role in Mox-LDL generation [26]. Indeed, the $\mathrm{O}_{2}^{-}$ generated by membrane NADPH oxidase is the starting substrate for generating hydrogen peroxide $\left(\mathrm{H}_{2} \mathrm{O}_{2}\right)$, a key substrate for MPO with regard to catalysing the production of $\mathrm{HOCl}$. It is the production of $\mathrm{HOCl}$ by MPO that allows production of Mox-LDL. Moreover, an increase in $\mathrm{H}_{2} \mathrm{O}_{2}$ in the $\mathrm{CC}$ compared to the cubital vein has been reported by Yeni et al. [27]. Those observations may explain why Mox-LDLs were increased in CC blood, suggesting also a local inflammatory phenomenon despite the fact that there was no correlation with the IIEF score.

Diabetic patients with ED have been shown to have increased endothelial apoptotic cell density in the CC [28]. IL-18 is expressed secondarily to inflammasome induction, which is mostly restricted to monocytes/macrophages. Previously, we observed that Mox-LDL could trigger an inflammasome on monocytes/macrophages (unpublished data). These effects suggest that the increase in IL-18 in the CC could be linked to the blood monocytes/macrophages triggered by the increase in Mox-LDL.

It is noteworthy that adiponectin was diminished $(+/-20 \%)$ in CC blood compared to the arm. Several studies have reported endothelial protective effects of adiponectin, such as suppression of apoptosis [29,30], activation of eNOS and an increase in NO production. In our cohort, no correlation between adiponectin and the IIEF score was observed. However, we cannot exclude a local loss of the protective function of adiponectin, acting against the proapoptotic effect of IL-18.

NO plays a central role in vasodilation and erection. HOCl-modified LDL [31] has been documented to induce eNOS mislocalisation, leading to a decrease in NO production. Previously, we also showed that MoxLDL decreased cGMP in endothelial cells. In the current study, our in vitro experiments showed that IL-18 and Mox-LDL significantly decreased eNOS mRNA expression in endothelial cells by $+/-25 \%$. Indeed, erectile and endothelial dysfunction may share some pathways through a defect in nitric oxide activity. Interestingly, IL-8 secretion was not increased by IL-18 in vitro in 
contrast to LDL, Mox-LDL and TNF- $\alpha$ (Figure 2). One explanation for this statistical interaction could be that the IL-8 level reflects a dysfunctional status of the endothelial cells, which may be more reactive than the biological effect of IL-18.

One major limitation of this study is that the design does not allow us to emphasise a clear role for IL-8 and IL-18 in ED. Oxidative stress and IL-18 are increased in CC of patients with no complaint of ED. Even if oxidative stress markers are increased in the corpus cavernosum, there is no difference in terms of erectile dysfunction prediction between the arm and corpus cavernosum potentially due to the fact that the population included patients with a low morbidity condition. Moreover, we cannot exclude an influence of the concentrations of inflammatory markers in CC on their concentrations in arm the impact of the inflammation markers is therefore difficult to assess with certainty and there is always space for ED evaluation and interpretation. This state could be a physiological condition and deserves continued consideration to explore levels in patients with complaints of ED with or without cardiovascular comorbidities. In addition, the same investigation could be carried out with patients complaining for clinical ED by vascular evaluation of ED with colour penile Doppler which aims at identifying contributing arterial and venous abnormalities [32]. Indeed, impaired endothelial function is considered as predictive of poor cardiovascular health and can be measured via several peripheral methods in ED patients to identify those patients with higher cardiovascular risk [33]. This is emphasised by Vardi et al. who reported evidence of focal impairment of the endothelial function in penis of ED patients [34] without the need for significant peripheral disease.

\section{Conclusions}

The endothelium plays a key role in maintaining tone and vascular integrity through the synthesis and release of NO. The decrease in NO production by oxidative stress, inflammation, and endothelial cell apoptosis contributes to the vascular aetiology of ED.

This study highlights the importance of inflammation in the CC compared to the peripheral venous blood and shows an interaction of inflammatory markers, such as IL-8 and IL-18, with the clinical erectile score reported by patients. These preliminary results need to be confirmed before to conclude to a potential use in clinical evaluation. Moreover, the difference in inflammatory marker concentrations in the venous blood and the CC highlights the importance of the site of the blood sample and should be taken into account in future studies with the difficulty and the inconvenience of cavernous blood uptake. Our results also show the need to study interactions among various blood parameters and endothelial cells. In addition, the increase in inflammatory markers (Mox-LDL and IL-18) in CC blood compared to arm blood in patients with no clinical ED is in accordance with the identification of ED as a sentinel symptom for upcoming CVD and also the consequence of local effect. A prospective study is needed including ED patients with objective evaluation of endothelial dysfunction to identify men with vasculogenic ED at higher risk for cardiovascular diseases.

\section{Acknowledgements}

The authors thank Pierrick Uzureau for his help in the last version of this manuscript.

\section{Disclosure statement}

No potential conflict of interest was reported by the authors.

\section{References}

1. Solomon H, Man JW, Jackson G. Erectile dysfunction and the cardiovascular patient: endothelial dysfunction is the common denominator. Heart 2003;89:251-253.

2. Lue TF. Erectile dysfunction. N Engl J Med 2000;342: 1802-1813.

3. Roumeguère Th, Wespes $E$, Carpentier $Y$, Hoffmann $P$, Schulman CC. Erectile dysfunction is associated with a high prevalence of hyperlipidemia and coronary heart disease risk. Eur Urol 2003;44:355-359.

4. Ponholzer A, Temml C, Obermayr R, Wehrberger C, Madersbacher $\mathrm{S}$. Is erectile dysfunction an indicator for increased risk of coronary heart disease and stroke? Eur Urol 2005;48:512-8; discussion 517.

5. Billups KL. Erectile dysfunction as a marker for vascular disease. Curr Urol Rep 2005;6:439-444.

6. Stokes KY, Cooper D, Tailor A, Granger DN. Hypercholesterolemia promotes inflammation and microvascular dysfunction: role of nitric oxide and superoxide. Free Radic Biol Med 2002;33:1026-1036.

7. Nicholls SJ, Hazen SL. Myeloperoxidase and cardiovascular disease. Arterioscler Thromb Vasc Biol 2005;25: 1102-1111.

8. Zhang R, Brennan ML, Fu X, Aviles RJ, Pearce GL, Penn $M S$, et al. Association between myeloperoxidase levels and risk of coronary artery disease. JAMA 2001;286: 2136-2142.

9. Zouaoui Boudjeltia $K$, Roumeguère Th, Delree $P$, Moguilevsky N, Ducobu J, Vanhaeverbeek $M$, et al. Presence of LDL modified by myeloperoxidase in the penis in patients with vascular erectile dysfunction: a preliminary study. Eur Urol 2007;51:262-8; discussion 268.

10. Boudjeltia KZ, Legssyer I, Van Antwerpen $\mathrm{P}$, Lema Kisoka R, Babar S, Moguilevsky N, et al. Triggering of 
inflammatory response by myeloperoxidase-oxidized LDL. Biochem Cell Biol 2006;84:805-812.

11. Roumeguère $T$, Boudjeltia $K Z$, Vanhaeverbeek $M$. Effect of $\mathrm{LDL}$ modified by myeloperoxidase- $\mathrm{H} 2 \mathrm{O} 2-\mathrm{Cl}(-)$ system on intracellular cyclic guanosine monophosphate level of endothelial cells: a link to erectile dysfunction? Eur Urol 2009;55:754-755.

12. Vlachopoulos C, Aznaouridis K, loakeimidis N, Rokkas K, Vassiliadou C, Alexopoulos N, et al. Unfavourable endothélial and inflammatory state in erectile dysfunction patients with or without coronary artery disease. Eur Heart J 2006;27:2640-2648.

13. Chandrasekar B, Vemula $K$, Surabhi RM, Li-weber $M$, Owen Schaub LB, et al. Activation of intrinsic and extrinsic proapoptotic signaling pathways in interleukin-18-mediated human cardiac endothelial cell death. J Biol Chem 2004;279:20221-20233.

14. Jefferis BJ, Papacosta O, Owen CG, Wannamethee SG, Humphries S, Woodward $\mathrm{M}$, et al. Interleukin 18 and coronary heart disease: prospective study and systematic review. Atherosclerosis 2011;217:227-233.

15. Moguilevsky N, Zouaoui Boudjeltia K, Babar S, Delrée P, Legssyer I, Carpentier Y, et al. Monoclonal antibodies against LDL progressively oxidized by myeloperoxidase react with ApoB-100 protein moiety and human atherosclerotic lesions. Biochem Biophys Res Commun 2004;323:1223-1228.

16. Franck $T$, Kohnen $S$, Boudjeltia $K Z$, et al. A new easy method for specific measurement of active myeloperoxidase in human biological fluids and tissue extracts. Talanta 2009;80:723-729.

17. Havel RJ, Eder HA, Bragdon JH. The distribution and chemical composition of ultracentrifugally separated lipoproteins in human serum. J Clin Invest 1955;34: 1345-1353.

18. Moguilevsky N, Garcia-Quintana L, Jacquet A, Tournay C, Fabry L, Piérard L, et al. Structural and biological properties of human recombinant myeloperoxidase produced by Chinese hamster ovary cell lines. Eur J Biochem 1991;197:605-614.

19. Delporte C, Boudjeltia KZ, Noyon C, Furtmüller PG, Nuyens $V$, Slomianny MC, et al. Impact of myeloperoxidase-LDL interactions on enzyme activity and subsequent posttranslational oxidative modifications of apoB-100. J Lipid Res 2014;55:747-757.

20. Kleiner G, Marcuzzi A, Zanin V, Monasta L, Zauli G. Cytokine levels in the serum of healthy subjects. Mediators Inflamm 2013;2013:434010.

21. Welsh P, Woodward M, Rumley A, Lowe G. Associations of plasma pro- inflammatory cytokines, fibrinogen, viscosity and C-reactive protein with cardiovascular risk factors and social deprivation: the fourth Glasgow Monica study. Br J Haematol 2008;141:852-861.

22. Jefferis $B J$, Whincup $P H$, Welsh $P$, Wannamethee $S G$, Rumley A, Ebrahim S, et al. Prospective study of IL-18 and risk of $\mathrm{Ml}$ and stroke in men and women aged 60-79 years: a nested case-control study. Cytokine 2013;61:513-520.
23. Aoun F, Albisinni $S$, Chemaly AK, Zanaty $M$, Roumeguère $T$. In search for a common pathway for health issues in men - the sign of a Holmesian deduction. Asian Pac J Cancer Prev 2016;17:1-13.

24. Montorsi P, Ravagnani PM, Galli S, Rotatori F, Veglia F, Briganti $A$, et al. Association between erectile dysfunction and coronary artery disease. Role of coronary clinical presentation and extent of coronary vessels involvement: the COBRA trial. Eur Heart J 2006;27:2632-2639.

25. Giugliano F, Esposito K, Di Palo C, Ciotola M, Giugliano $G$, Marfella $R$, et al. Erectile dysfunction associates with endothelial dysfunction and raised proinflammatory cytokine levels in obese men. J Endocrinol Invest 2004;27:665-669.

26. Zouaoui Boudjeltia K, Moguilevsky N, Legssyer I, Babar $S$, Guillaume $M$, Delree $P$, et al. Oxidation of low density lipoproteins by myeloperoxidase at the surface of endothelial cells: an additional mechanism to subendothelium oxidation. Biochem Biophys Res Commun 2004;325:434-438.

27. Yeni E, Gulum M, Selek S, Erel O, Unal D, Verit A, et al. Comparison of oxidative/antioxidative status of penile corpus cavernosum blood and peripheral venous blood. Int J Impot Res 2005;17:19-22.

28. Costa C, Soares R, Castela A, Adães S, Hastert V, Vendeira $P$, et al. Increased endothelial apoptotic cell density in human diabetic erectile tissue: Comparison with clinical data. J Sex Med 2009;6:826-835.

29. Kobayashi H, Ouchi N, Kihara S, Walsh K, Kumada M, Abe $Y$, et al. Selective suppression of endothelial cell apoptosis by the high molecular weight form of adiponectin. Circ Res 2004;94:e27-e31.

30. Cheng KK, Lam KS, Wang Y, Huang Y, Carling D, Wu D, et al. Adiponectin-induced endothelial nitric oxide synthase activation and nitric oxide production are mediated by APPL1 in endothelial cells. Diabetes 2007;56:1387-1394.

31. Nuszkowski A, Gräbner R, Marsche G, Unbehaun A, Malle $E$, Heller R. Hypochlorite-modified low density lipoprotein inhibits nitric oxide synthesis in endothelial cells via an intracellular dislocalization of endothelial nitric-oxide synthase. J Biol Chem 2001;276: 14212-14221.

32. Seager CM, Li J, Shoskes DA. Lack of predictive correlation between peripheral arterial tone and colour flow Doppler parameters in men with erectile dysfunction. BJU Int 2013;112:E186-E190.

33. Kovac JR, Gomez L, Smith RP, Coward RM, Gonzales $M A$, Khera $M$, et al. Measurement of endothelial dysfunction via peripheral arterial tonometry predicts vasculogenic erectile dysfunction. Int J Impot Res 2014;26:218-222.

34. Vardi Y, Dayan L, Apple B, Gruenwald I, Ofer Y, Jacob G. Penile and systemic endothelial function in men with and without erectile dysfunction. Eur Urol 2009;55:979-985. 